Research Article

\title{
Further Understanding of Uncertainties in the Impedance Spectrum of the Polymer Electrolyte Fuel Cell due to Inductive Effects and Oxygen Diffusion Time Constant
}

\author{
Samuel Cruz-Manzo *
}

School of Engineering, University of Lincoln, Lincolnshire, LN6 7TS, United Kingdom; E-Mail: scruzmanzo@lincoln.ac.uk

* Correspondence: Samuel Cruz-Manzo; E-Mail: scruzmanzo@lincoln.ac.uk

Academic Editor: Zhao Yang Dong

Journal of Energy and Power Technology

2020 , volume 2 , issue 4

doi:10.21926/jept.2004017
Received: July 31, 2020

Accepted: November 16, 2020

Published: November 24,2020

\begin{abstract}
In this study, uncertainties during the assessment of the electrochemical impedance spectrum of the polymer electrolyte fuel cell (PEFC) attributed to inductive artefacts at high frequencies and inductive loops at low frequencies as well as oxygen diffusion time constant are discussed. A validated impedance model represented as an equivalent electrical circuit of a PEFC allowed the simulation of the effect of inductive artefacts, inductive loops and oxygen diffusion time constant on electrochemical impedance spectroscopy (EIS) measurements represented in the Nyquist plot. This study considers EIS measurements reported in previous studies and provides an insight into the EIS measurements with positive imaginary components at high frequencies attributed to the intrinsic inductance of the measurement cables during EIS tests and at low frequencies attributed to electrochemical mechanisms (e.g. side reactions with intermediate species) during PEFC operation. In addition, an overview of overlapping mechanisms (charge transfer and oxygen transport resistances during the oxygen reduction reaction) on the PEFC impedance spectrum attributed to oxygen diffusion across the cathode catalyst layer is presented. EIS measurements with positive imaginary components and with overlapping effects could yield to ambiguities when studying or relating electrochemical mechanisms (ion conduction, capacitance, charge transfer and mass transport resistances) of
\end{abstract}

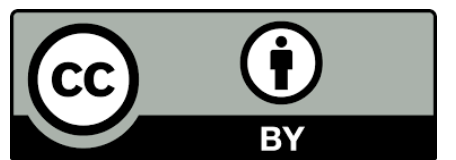

(c) 2020 by the author. This is an open access article distributed under the conditions of the Creative Commons by Attribution License, which permits unrestricted use, distribution, and reproduction in any medium or format, provided the original work is correctly cited. 
the PEFC through a defined single frequency or a single measured value represented in the Nyquist complex-impedance plot.

\section{Keywords}

Electrochemical impedance spectroscopy; polymer electrolyte fuel cell; electrical circuit model; inductive effect

\section{Introduction}

Polymer electrolyte fuel cells (PEFC) are electrochemical devices that convert the chemical energy of hydrogen into electricity during a (hydrogen-oxidation and oxygen-reduction) redox process. Electrochemical impedance spectroscopy (EIS) is an in in-situ and non-invasive experimental technique which allows the characterisation of the different electrochemical mechanisms during PEFC operation. EIS has demonstrated to be a resourceful experimental technique to monitor the state-of-health and consequently the performance of the polymer electrolyte fuel cell (PEFC). Studies in the literature have applied the EIS technique to monitor the performance or study electrochemical mechanisms of the PEFC at different operating conditions [16].

Some studies have identified, through a graphical interpretation of the Nyquist plot, the electrochemical and diffusion mechanisms during the oxygen reduction reaction (ORR) in the PEFC. EIS has been applied to PEFC stacks to diagnose failures or performance deterioration attributed to flooding or drying effects during PEFC stack operation. The state of health of PEFC stacks during drying and flooding conditions has been studied by Kurz et al. [7]. 6-cell PEFC stack impedance spectra were measured through a multichannel impedance analyzer in the study and shows that the impedance measurements at two specific frequencies, one high $(1 \mathrm{kHz})$ and one low frequency impedance $(0.5 \mathrm{~Hz})$ are a good indicator to predict voltage drops caused by drying and flooding. A Proportional Integral Derivative (PID) control strategy, which has the voltage drop as input variable and the required air flux for the stack to overcome the two failure modes as the output variable, operated the stack fully autonomously and was able to prevent all voltage drops caused by flooding. In the study reported by Merida et al. [8] two PEFC failure modes (dehydration and flooding) were investigated through EIS on a 4-cell PEFC stack. The authors also demonstrated that these two extreme failure modes can be distinguished by impedance measurements in different frequency bands. Dehydration was simulated by switching the oxidant in one cell between saturated and dry air streams at the same temperature and maintaining constant humidification in the remaining cells. EIS spectra were measured as the cell potential decreases and the varying spectra were compared to the spectra obtained before switching the reactant. Flooding effect was simulated by altering the reactant stoichiometry of the oxidant flow downstream from an individual cell within the PEFC stack. The dehydration effects were measurable over the frequency range $0.5-100 \mathrm{kHz}$, while the flooding effects were measurable in the frequency range $0.5-100 \mathrm{~Hz}$. Additionally, in the study of Yuan et al. [9] a diagnosis of a 500 W Ballard Mark V PEFC stack was evaluated through EIS. Three characteristic semicircles were presented in the spectra. A bigger semicircle from $1 \mathrm{kHz}$ to $0.1 \mathrm{~Hz}$ was reported to reflect the behaviour of the stack cathode. This semicircle corresponds to the charge transfer 
process of the ORR. Moreover, other studies have demonstrated that a smaller semicircle (high frequency loop, from $2 \mathrm{kHz}$ to $1 \mathrm{kHz}$ ) has been associated to structural features of the membrane electrode assembly (MEA) [10] and distributed resistance effects in the electrolyte within the catalyst layer (CL) [11].

The interpretation of the physical processes of the PEFC through EIS measurements can be obscured as uncertainties during the assessment of EIS measurements can be attributed to artefacts (inductive effects) from the measurement hardware as well as to overlapping effects (different physical processes) on the impedance characteristics. These uncertainties could yield to ambiguities when studying or relating electrochemical mechanisms (ion conduction, capacitance, charge transfer and mass transport resistances) of the PEFC through a single measured value of EIS measurements represented in the Nyquist complex-impedance plot.

The inductive effect at high frequencies on the impedance spectrum has been reported in the literature $[1,12,13]$. This effect deforms the high frequency region of the impedance spectrum and yields an erroneous structural interpretation on the impedance spectrum [14, 15]. With regard to inductive effect at low frequencies, these measurements have been coined as inductive loops and have been attributed to side reactions with intermediate species [4, 16], carbon monoxide poisoning [17], and water transport characteristics [5]. A literature review on inductive loops of EIS measurements in PEFCs has been carried out by Pivac and Barbir [18].

The separation of the different time constants of frequency arcs in EIS measurements of PEFCS has been considered in the literature. These features are associated to different electrochemical processes during PEFC operation. Weiß et al. [19] applied the method of Distribution of Relaxation Times (DRT) to analyze the impedance spectra of a high-temperature PEFC doped with phosphoric acid. In the DRT method, the system is modelled by an infinite series formed by a parallel configuration between a capacitor and a resistor. It is possible to separate the individual processes by associating their time constants with the associated R//C elements. The use of the DRT method has also been considered to decouple individual processes in impedance spectra of solid oxide PEFCs [20].

In this study, EIS measurements carried out in PEFCs and reported in previous studies [21-23] which feature positive imaginary components at high and low frequencies attributed to the intrinsic inductance of the measurement cables during EIS tests $[14,15]$ and electrochemical mechanisms (e.g. side reactions with intermediate species $[18,24]$ ) during PEFC operation are re-considered. In addition, EIS measurements featuring an overlapping effect in the Nyquist plot between kinetics of the ORR and oxygen diffusion mechanisms during PEFC operation are re-considered. The aim of this study is to provide an insight into the issues and errors that EIS measurements with positive imaginary components, and with overlapping effects, can generate when estimating electrochemical processes (ion conduction, capacitance, charge transfer, diffusion mechanisms and side reactions during the ORR) in PEFCs through a defined single frequency or a single measured value in the Nyquist complex-impedance plot.

The application of the impedance model presented in this study to experimental EIS measurements in PEFCs demonstrates how artefacts from the measurement hardware as well as overlapping processes in the electrode during PEMFC operation could yield to an incorrect assessment of electrochemical and diffusion processes that occur at different rates within the PEFC. The impedance model allows the separation and estimation of PEFC processes represented in the impedance spectrum and resulted from EIS. 


\section{Equivalent Electrical Circuit for EIS Analysis}

Equivalent electrical circuits (EECs) are commonly considered to estimate electrochemical processes represented in the EIS response of the PEFC. The impedance response from an EEC is commonly fitted to the impedance response of the PEFC using a non-linear regression method. Different configurations of EECs have been reported in the literature $[1,25]$ to characterize different processes in a PEFC during EIS. The Randles circuit $[12,26,27]$ can characterize the electrochemical mechanisms in the electrode/electrolyte interface of a PEFC. It consists of a double-layer capacitance for the interface between the dissimilar materials, i.e., the carbon / nafion interface (nafion as electrolyte), and; (ii) a parallel resistance to charge transfer across the same interface, as shown in Figure $1 \mathrm{~A}$ Warburg element which describes resistance of diffusion of chemical species through a finite diffusion medium at the frequency domain and derived from Fick's second law and Faraday's law has been broadly used together with the Randles circuit configuration to account for oxygen transport limitations at high currents in EIS measurements. The Randles circuit shown in Figure 1 does not take into account the ionic resistance in the catalyst layer (CL) of PEFCs.

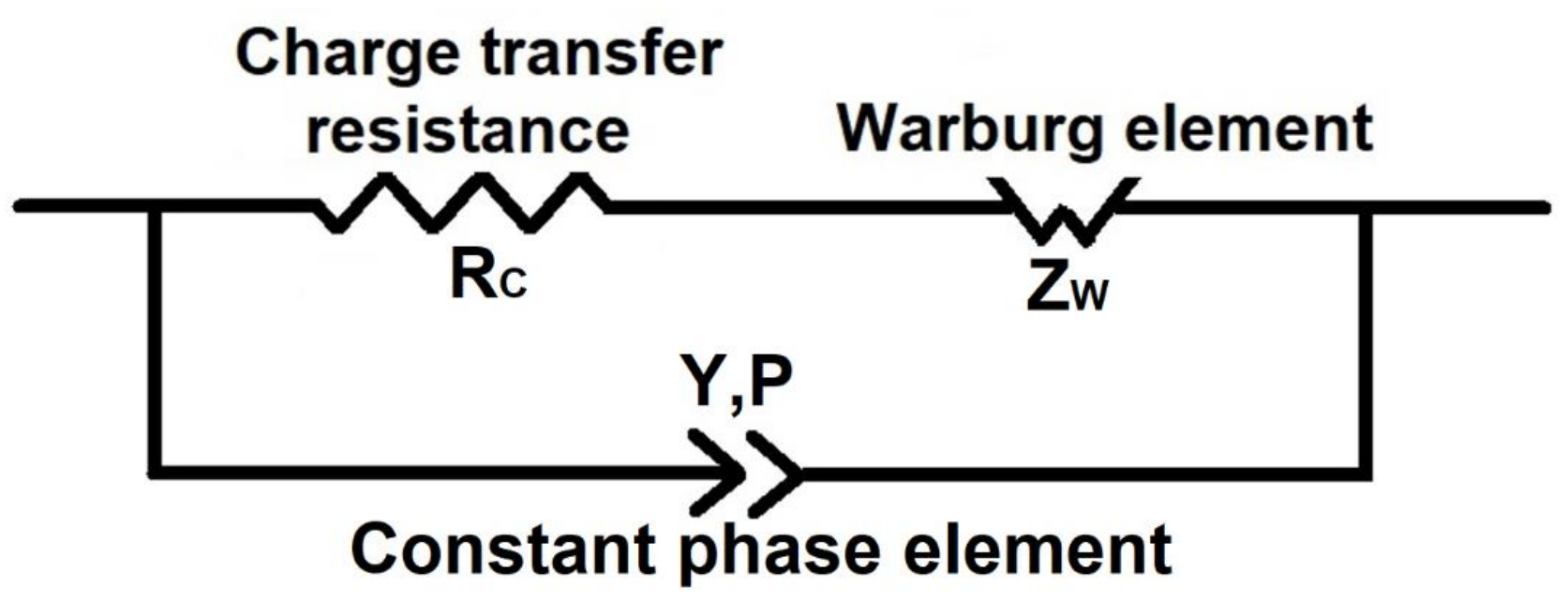

Figure 1 Randles circuit to characterise the electrode/electrolyte interface of a PEFC.

The impedance of the Randles circuit shown in Figure 1 can be represented as:

$$
Z_{\text {Randles }}=\frac{\mathrm{R}_{\mathrm{C}}+\mathrm{Z}_{\mathrm{w}}}{1+\mathrm{Y}(\mathrm{j} \omega)^{\mathrm{P}}\left(\mathrm{R}_{\mathrm{C}}+\mathrm{Z}_{\mathrm{w}}\right)}
$$

where $R_{C}$ is the charge transfer resistance during the ORR, $Y$ and $P$ are parameters related to a constant phase element (CPE) to account for the nonhomogeneous charge distribution (capacitance) between dissimilar materials e.g. carbon/electrolyte, $\omega$ is the angular frequency, $j$ is the imaginary component of a complex number, and $Z w$ is the finite-length Warburg component to account for oxygen transport limitations during EIS and is defined as:

$$
\mathrm{Z}_{\mathrm{W}}=\mathrm{R}_{\mathrm{W}} \frac{\tanh \left(\mathrm{j} \omega \tau_{\mathrm{W}}\right)^{0.5}}{\left(\mathrm{j} \omega \tau_{\mathrm{W}}\right)^{0.5}}
$$

with

$$
\mathrm{R}_{\mathrm{W}}=\frac{\mathrm{RT} \delta}{\mathrm{z}^{2} \mathrm{~F}^{2} \mathrm{c}_{\mathrm{O}}^{*} \mathrm{D}}
$$


where $R_{W}$ is defined as the resistance for the oxygen diffusion process, $R$ is the gas constant, $T$ is the temperature, $F$ is the Faraday constant, $z$ is the number of electrons consumed, $D$ is the oxygen diffusion coefficient, $c_{O}^{*}$ is the oxygen bulk concentration, $\delta$ represents the characteristic length scale of the diffusive process in the electrode

and

$$
\tau_{\mathrm{W}}=\frac{\delta^{2}}{\mathrm{D}}
$$

defined as the time constant to diffuse oxygen through the electrode.

An equivalent network formed by a parallel configuration between a capacitor and a resistor has been connected in series with the charge transfer resistance of the EEC as shown in Figure 2 to account for a side reaction with adsorbed intermediate species during the ORR [28]. Ciureanu and Wang [29] reported the same EEC shown in Figure 2 to account for an electrode with adsorbed intermediate species at the interface between dissimilar materials i.e. nafion-carbon. Moreover, the circuit shown in Figure 2 was used to study the influence of $\mathrm{CO}$ poisoning on the platinum gas diffusion electrodes of PEFCs through EIS measurements [30, 31].

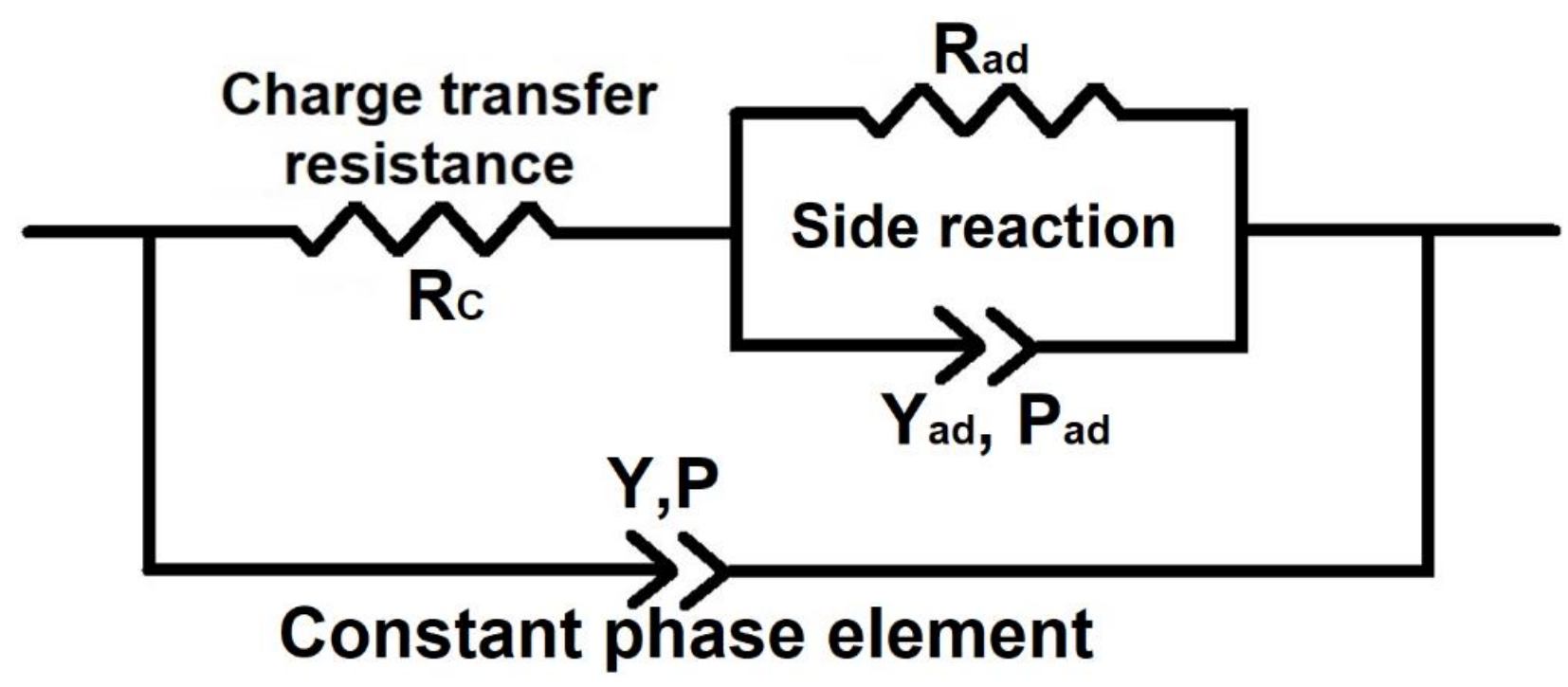

Figure 2 Electrical circuit to characterise side reactions with intermediate species during the reduction reaction.

The impedance of the EEC shown in Figure 2 can be represented as:

$$
Z=\frac{\mathrm{R}_{\mathrm{C}}+\mathrm{Z}_{\mathrm{ad}}}{1+\mathrm{Y}(\mathrm{j} \omega)^{\mathrm{P}}\left(\mathrm{R}_{\mathrm{C}}+\mathrm{Z}_{\mathrm{ad}}\right)}
$$

with

$$
\mathrm{Z}_{\mathrm{ad}}=\frac{\mathrm{R}_{\mathrm{ad}}}{1+\mathrm{Y}_{\mathrm{ad}}(\mathrm{j} \omega)^{\mathrm{P}_{\mathrm{ad}} \mathrm{R}_{\mathrm{ad}}}}
$$

where Eq. 6 is the impedance response of the parallel configuration between a CPE $\mathrm{Cd}\left(Y_{a d}, P_{a d}\right)$, and a resistor $R_{a d}$ to account for a side reaction with adsorbed intermediate species during the ORR.

An alternative model, a transmission line circuit (TLC) to represent the impedance and to characterise the porous $\mathrm{CL}$ of PEFCs has been considered in some studies [32-36]. Figure 3 shows 
the configuration of the TCL to characterise the impedance response of the porous CL of PEFCs. The TLC consists of an upper rail to account for the ionic conduction, and a lower rail to represent the electron access in the $\mathrm{CL}$. In the upper rail distributed resistances to account for the ionic resistance in the $\mathrm{CL}$ electrolyte are considered. Usually the distributed electron resistances are neglected to simplify the mathematical analysis because the resistance to ion transfer in the electrolyte of the $\mathrm{CL}$ is greater than the resistance to the electron transfer in the carbon of the CL. Between the upper rail and lower rail, parallel distributed resistors and capacitors to account for the charge transfer resistance and the double-layer capacitance effect between the nafion/carbon interface are considered. The TLC shown in Figure 3 cannot characterise the cathode catalyst layer (CCL) operated at high currents during EIS because it does not consider the Warburg element to account for oxygen transport limitations in the CCL.

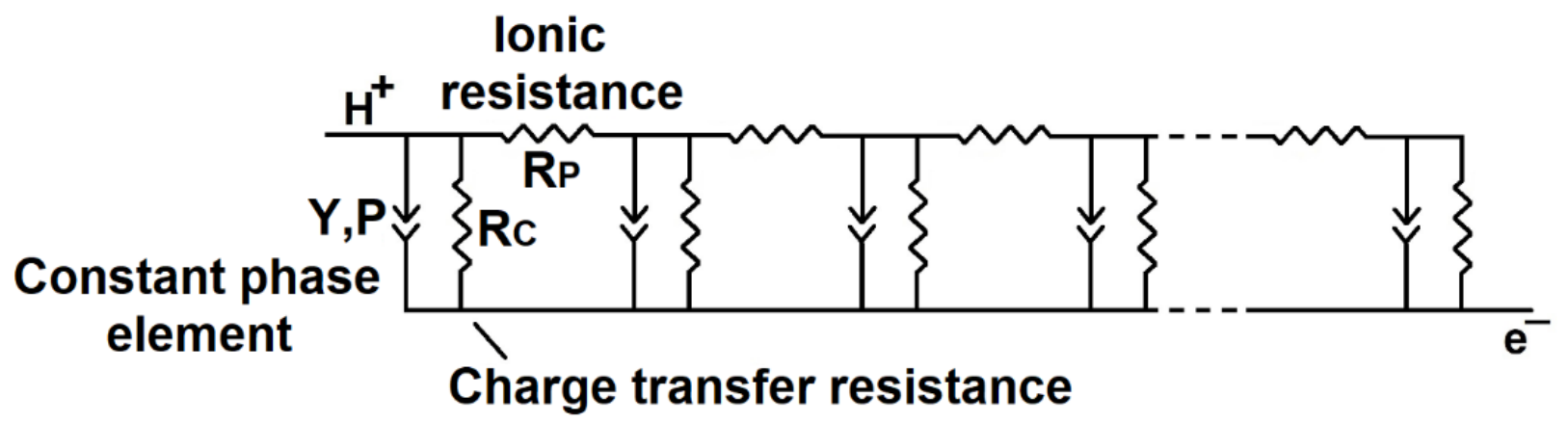

Figure 3 Transmission line circuit to characterise the porous catalyst layer of PEFCs.

The impedance of the TLC shown in Fig. 3 can be represented as:

$$
Z_{T L C}=\frac{\mathrm{R}_{\mathrm{C}} \lambda \operatorname{coth}(\lambda \mathrm{x})}{1+\mathrm{Y}(\mathrm{j} \omega)^{\mathrm{P}} \mathrm{R}_{\mathrm{C}}}
$$

with

$$
\lambda=\sqrt{\mathrm{R}_{\mathrm{P}}\left[\frac{1}{\mathrm{R}_{\mathrm{C}}}+\mathrm{Y}(\mathrm{j} \omega)^{\mathrm{P}}\right]}
$$

where $R_{P}$ is the ionic resistance in the $C L$ and $x$ represents the nondimensional thickness of the $C L$ and for EIS measurements in PEFCs (lumped parameters) is equal to 1.

In a previous study [21], the EEC shown in Figure 4 was constructed from fundamental electrochemical theory to simulate the frequency response of the cathodic side of a PEFC during EIS tests. The impedance response of the cathodic side of a PEFC can be measured using a threeelectrode configuration during EIS tests [23]. The EEC shown in Figure 4 can also simulate the frequency response of a whole PEFC during EIS tests if no contaminants in the anode are present during PEFC operation and overpotentials related to the hydrogen oxidation reaction (HOR) are neglected. 


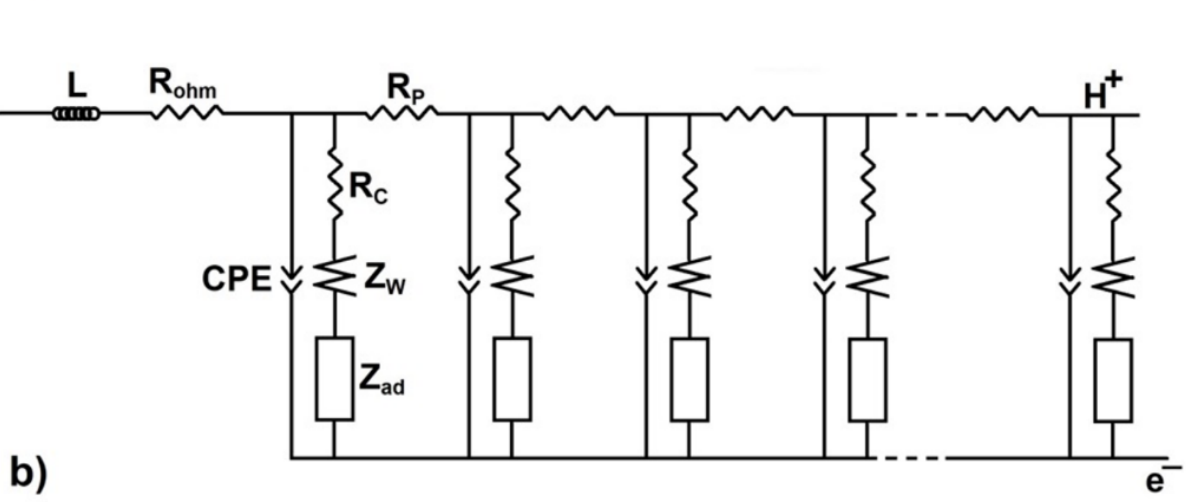

Figure 4 a) Ion and electron conduction through the cathode catalyst layer, b) Representation of an equivalent electrical circuit for analysis of cathodic EIS or PEFC-EIS (no anode contribution). Transmission line circuit considering oxygen transport limitations and side reactions during the oxygen reduction reaction.

The EEC shown in Figure $4 \mathrm{~b}$ can provide an appropriate description of the agglomeration of platinum particles supported on carbon and surrounded by the electrolyte for ion conduction in the $\mathrm{CCL}$, as shown in Figure 4a. The EEC shown in Figure $4 \mathrm{~b}$ combines the electrical components of the EECs previously shown in Figures 1-3. It can be observed in the EEC shown in Figure $4 \mathrm{~b}$ that each branch connected between the upper and lower rails comprises the components of the EECs shown in Figures 1-3 and represents the various steps during the ORR. Bard and Faulkner [37] reported that the overpotential during an electrochemical reaction can be considered as a sum of terms associated with the different reaction processes: mass transport overpotential, charge transfer overpotential and overpotential associated with a preceding reaction.

The EEC shown in Figure $4 \mathrm{~b}$ considers an upper rail of resistors to account for the resistance $R_{P}$ for ion $\mathrm{H}^{+}$conduction across the electrolyte surrounding the agglomerates in the $\mathrm{CCL}$. The lower rail considers that the resistance for electron $\mathrm{e}^{-}$conduction through the carbon in the $\mathrm{CCL}$ is neglected [13]. A resistor to account for the charge transfer resistance $R_{C}$ during the ORR, a CPE to account for the nonhomogeneous charge distribution (capacitance) between dissimilar materials e.g. carbon/electrolyte, and a Warburg component $Z_{w}$ (Eq. 2) to account for oxygen transport limitations during the ORR are distributed and connected between the upper and lower rails. The Warburg component $Z_{W}$ is comprised of a resistance for oxygen diffusion $R_{W}$ (Eq. 3) and a time constant for oxygen diffusion $\tau_{W}$ (Eq. 4) as well.

The EEC also considers the impedance of an additional equivalent network (parallel configuration between a capacitor and a resistor) represented through the component $Z_{a d}$ (Eq. 6) to account for side reactions with intermediate adsorbed species during the ORR. This equivalent network to represent the side reactions is shown in Figure 2 . The component $Z_{a d}$ simulates inductive loops (impedance response with positive imaginary components) at low frequencies. A resistor $R_{\text {ohm }}$ is connected in series with the TLC to account for the total ohmic resistance in the polymer electrolyte membrane (PEM), gas diffusion layers (GDLs), and flow field plates (FFPs). An inductor $L$ is also 
connected in series with the total ohmic resistance $R_{\text {ohm }}$ to account for the inductance of the measurement cables of the EIS hardware.

The impedance response of the EEC shown in Figure $4 \mathrm{~b}$ can be represented through the following equation:

$$
Z_{F C}=L(j \omega)+R_{o h m}+\frac{\left(R_{C}+Z_{w}+Z_{a d}\right) \gamma \operatorname{coth}(\gamma x)}{1+Y(j \omega)^{P}\left(R_{C}+Z_{w}+Z_{a d}\right)}
$$

where

$$
\gamma=\sqrt{R_{P}\left[\frac{1}{R_{C}+Z_{w}+Z_{a d}}+Y(j \omega)^{P}\right]}
$$

The impedance response of the EEC shown in Figure 4 and represented through Eq. 9 mainly considers the electrochemical mechanisms that take place in the CCL of the PEFC, as the physical mechanisms within the adjacent layers have an influence on the CCL performance. For instance, oxygen transport limitations on the GDL and FFP will have an influence on the concentration $\mathrm{c}_{0}^{*}$ at the CCL-GDL interface which is represented in Eq. 3. More details of the mathematical derivation of the impedance equation represented in Eq. 9 can be found elsewhere [21].

It is well known that the increase of parameters in an EEC improves the fitting results with EIS measurements. It is possible to reduce the number of fitted parameters in an EEC with the EIS measurements by estimating parameters from theoretical relations reported in literature and through a graphical interpretation of the Nyquist complex plot $[22,23]$. This provides assurance that the parameters in the EEC shown in Figure $4 \mathrm{~b}$ and represented in Eq. 9 can correctly relate the physics and chemistry that are occurring. The EEC shown in Figure $4 \mathrm{~b}$ has been applied and validated with EIS measurements carried out in an open-cathode PEFC stack [21] and single $\mathrm{H}_{2} /$ air PEFCs [23, 38-40].

\section{Simulating EIS Measurements with Positive Imaginary Components in the Nyquist Plot}

EIS measurements with positive imaginary components are related to inductive effects. These measurements in the high frequency range have been attributed to the inductance of the electrical cables connected between the PEFC and the load during EIS tests [14, 15]. In the low frequency range (e.g. below $1 \mathrm{~Hz}$ ), EIS measurements with positive imaginary components have been coined as inductive loops and have been attributed to phenomenological processes (e.g. side reactions with intermediate species $[18,24])$ during PEFC operation. In previous studies $[22,38]$, it was possible to validate the inductive effect of the electrical cables at high frequencies and inductive loops at low frequencies in the impedance response of PEFCs using impedance models derived from electrode theory.

The simulated impedance spectrum generated from the EEC shown in Figure 4 presents two semicircles (EIS measurements with negative imaginary components $Z^{\prime \prime}$ ) in the Nyquist plot [12, 27] as shown in Figure 5. The first semicircle from high to low frequencies $(20 \mathrm{kHz}-2 \mathrm{~Hz}$ ) is mainly related to the driving force for the interfacial ORR process. Electrochemical mechanisms related to HOR could also be overlapped in this high frequency semicircle, but commonly are regarded as negligible if no contaminants are present during the HOR [13]. The semicircle with negative imaginary components $Z^{\prime \prime}$ at frequencies lower than $2 \mathrm{~Hz}$ and shown in Figure 5 is related to oxygen diffusion limitation during the ORR. In some cases, it is not possible to visualize a separation 
between both semicircles as these are overlapped in the Nyquist plot [23]. This overlapping effect makes it difficult to estimate the contribution of charge transfer process of the ORR and oxygen diffusion during EIS in PEFCs. This overlapping effect will be discussed in the next section. The total impedance of the PEFC could be calculated by considering the end-point of the impedance spectrum where the imaginary components are equal to zero $Z^{\prime \prime}=0$ at low frequencies. The total ohmic resistance comprising the PEM, GDLs, and FFPs can be calculated by considering the end-point of the impedance spectrum where the imaginary components are equal to zero $Z^{\prime \prime}=0$ at high frequencies. However, Figure 5 shows that the effect of the inductive effect at low and high frequencies on the impedance spectrum may yield an incorrect calculation of the total impedance and total ohmic resistance considering the two end-points of the impedance spectrum at $Z^{\prime \prime}=0$.

Table 1 Parameters of Eq. 9 to predict the spectrum with high and low inductive effect.

\begin{tabular}{|c|c|c|c|c|c|c|}
\hline $\begin{array}{l}\mathrm{R}_{\mathrm{P}} \\
\Omega . \mathrm{cm}^{2}\end{array}$ & $\begin{array}{l}\mathrm{Rc}_{\mathrm{c}} \\
\Omega . \mathrm{cm}^{2}\end{array}$ & $\begin{array}{l}Y \\
s^{P} \Omega^{-1} \cdot \mathrm{cm}^{-2}\end{array}$ & $\mathrm{P}$ & $\begin{array}{l}\mathrm{Rw} \\
\Omega . \mathrm{cm}^{2}\end{array}$ & $\begin{array}{l}\text { Tw } \\
s\end{array}$ & $\begin{array}{l}\text { Rohm } \\
\Omega . \mathrm{cm}^{2}\end{array}$ \\
\hline \multirow[t]{3}{*}{0.3} & 0.6 & 0.034 & 0.81 & 0.236 & 0.41 & 0.16 \\
\hline & & & & $\mathrm{L}$ & $\mathrm{R}_{\mathrm{ad}}$ & $\mathrm{Y}_{\mathrm{ad}}$ \\
\hline & & & & $\mathrm{H}$ & $\Omega . \mathrm{cm}^{2}$ & $\mathrm{~s}^{\mathrm{P}} \Omega^{-1} \cdot \mathrm{cm}^{-2}$ \\
\hline \multicolumn{2}{|c|}{ High inductive effect } & & & $9 \times 10^{-6}$ & -0.205 & -42.2 \\
\hline \multicolumn{2}{|c|}{ Low inductive effect } & & & $9 \times 10^{-7}$ & -0.026 & -172.2 \\
\hline \multicolumn{2}{|c|}{ No inductive effect } & & & 0 & 0 & 0 \\
\hline
\end{tabular}

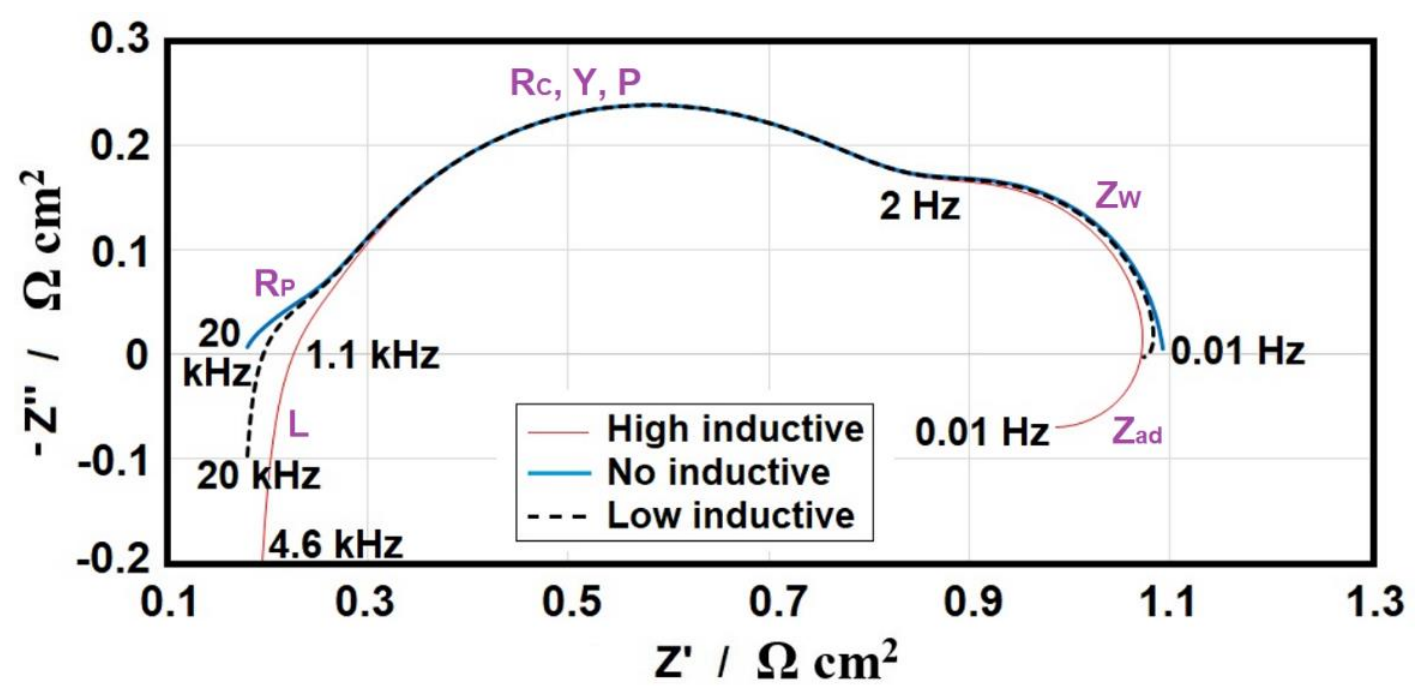

Figure 5 Simulated inductive effect at high frequencies and inductive loop at low frequencies on EIS measurements using Eq. 9 and parameters shown in Table 1.

In a recent study reported by Halvorsen et al. [41], it has been considered that the low frequency intercept of EIS measurements within the real axis at $Z^{\prime \prime}=0$ can assess the state of ageing in PEFCs. Niya et al. [42] reported that the frequency at which the spectrum intercepts the real axis at $Z^{\prime \prime}=0$ can be used to diagnose flooding in the GDL. Figure 5 demonstrates that the practice of using reference points e.g. end-points of the spectrum where $Z^{\prime \prime}=0$ or defining a specific frequency to develop generic algorithms for PEFC diagnostics may raise uncertainties when applying the algorithm to different PEFCs as the magnitude of inductive effects at high frequencies and low 
frequency loops during EIS may change for different PEFC systems. The difference between spectra containing different magnitude of inductive effects at high frequencies and low frequency loops may increase during EIS tests in large PEFC stacks and at different operating conditions. In addition, the characterisation of inductive loops through impedance models can yield uncertainties about the estimation of time constants from inductive loops. This will be discussed later.

\subsection{Inductive Effect at High Frequency}

The EEC shown in Figure 4 can simulate the inductance effect of the measurement cables connected between the PEFC and the load during EIS tests. The consequence of the inductive effect on the impedance spectrum at high frequencies is simulated using the circuit shown in Figure 4 with the parameters shown in Table 1 and considering different values of the inductor $L$. The value of the inductor $L$ from the circuit shown in Figure 4 was reduced from $L=9 \times 10^{-6} \mathrm{H}$ to $L=9 \times 10^{-7} \mathrm{H}$ to simulate the low inductance spectrum and it was also neglected $L=0$ to simulate the spectrum with no inductance effect of the high frequency region, as shown in Figure 5.

As reported by Merida et al. [8], it is possible to reduce the inductance of the electrical cables from the measurement EIS system by maintaining equal lengths in the cables, twisting the large current leads to the electronic load, and polishing and clamping the metal contacts. Figure 6 shows cathodic EIS measurements carried out in a $25 \mathrm{~cm}^{2} \mathrm{H}_{2}$ /air PEFC using conventional cables (high inductance spectrum) and special low inductance cables (low inductance spectrum) connected between the PEFC and the load during EIS tests. A three-electrode configuration allowed the measurement of the impedance response of the cathodic side of the PEFC. The operating conditions of the $25 \mathrm{~cm}^{2} \mathrm{H}_{2}$ /air PEFC and experimental setup for the cathodic EIS measurements shown in Figure 6 can be found in a previous study [38]. The EEC model shown in Figure 4 was fitted to the EIS measurements shown in Figure 6. The parameter $Z_{a d}=0$ was considered negligible in Eq. 9 as no inductive loops at low frequencies were manifested. The oxygen diffusion time constant $\tau_{W}$ considered during the fitting process between the EIS measurements shown in Figure 6 and the circuit shown in Figure 4 was with an order of magnitude of $10^{-3} \mathrm{~s}$ [23], as shown in Table 2. This order of magnitude for $\tau_{W}$ resulted from the overlapping effect between electrochemical mechanisms (charge transfer and oxygen diffusion resistances during the ORR) or the single semicircle represented in the Nyquist complex-impedance plot. This overlapping effect between electrochemical mechanisms on the impedance spectrum will be discussed later. The EEC model shown in Figure 4 was able to reproduce the inductive effect of the measurement cables on the high frequency region of the Nyquist plot, as shown in Figure $6 a$. The value of the inductor $L$ in the circuit shown in Figure 4 resulted in $L=6.77 \times 10^{-7} \mathrm{H}$ for the low inductance spectrum and $L=$ $2.07 \times 10^{-6} \mathrm{H}$ for the high inductance spectrum as shown in Table 2 . Similar results have been reported in a previous study [38]. The value of the inductor was also decreased to $L=$ $2.07 \times 10^{-10} \mathrm{H}$ to be considered as negligible in the simulated impedance spectrum and the simulated frequency was increased to $100 \mathrm{kHz}$ to observe a $45^{\circ}$ straight-line at high frequencies whose projection on the real component $Z^{\prime}$ represents the ionic resistance in the CCL [38], as shown in Figure 6a. A previous study [38] demonstrated that the simulated $45^{\circ}$ straight-line at high frequencies in the impedance spectrum started being apparent when the value of the inductor was considered to be with an order of magnitude of $10^{-9} \mathrm{H}$. 
Table 2 Parameters of Eq. 9 to predict the impedance spectrum with high and low inductive effect.

\begin{tabular}{|c|c|c|c|c|c|c|}
\hline $\begin{array}{l}\mathrm{R}_{\mathrm{P}} \\
\Omega . \mathrm{cm}^{2}\end{array}$ & $\begin{array}{l}\mathrm{Rc}_{\mathrm{c}} \\
\Omega . \mathrm{cm}^{2}\end{array}$ & $\begin{array}{l}Y \\
s^{P} \Omega^{-1} \cdot \mathrm{cm}^{-2}\end{array}$ & $P$ & $\begin{array}{l}\mathrm{R}_{\mathrm{w}} \\
\Omega . \mathrm{cm}^{2}\end{array}$ & $\begin{array}{l}T_{w} \\
s\end{array}$ & $\begin{array}{l}\text { Rohm } \\
\Omega . \mathrm{cm}^{2}\end{array}$ \\
\hline \multirow[t]{3}{*}{0.12} & 0.41 & 0.0382 & 0.82 & 0.26 & 0.003 & 0.195 \\
\hline & & & & $\mathrm{L}$ & $\mathrm{R}_{\mathrm{ad}}$ & $Y_{\text {ad }}$ \\
\hline & & & & $\mathrm{H}$ & $\Omega . \mathrm{cm}^{2}$ & $s^{P} \Omega^{-1} \cdot \mathrm{cm}^{-2}$ \\
\hline \multicolumn{2}{|c|}{ High inductive effect } & & & $2.07 \times 10^{-6}$ & 0 & 0 \\
\hline \multicolumn{2}{|c|}{ Low inductive effect } & & & $6.77 \times 10^{-7}$ & 0 & 0 \\
\hline
\end{tabular}
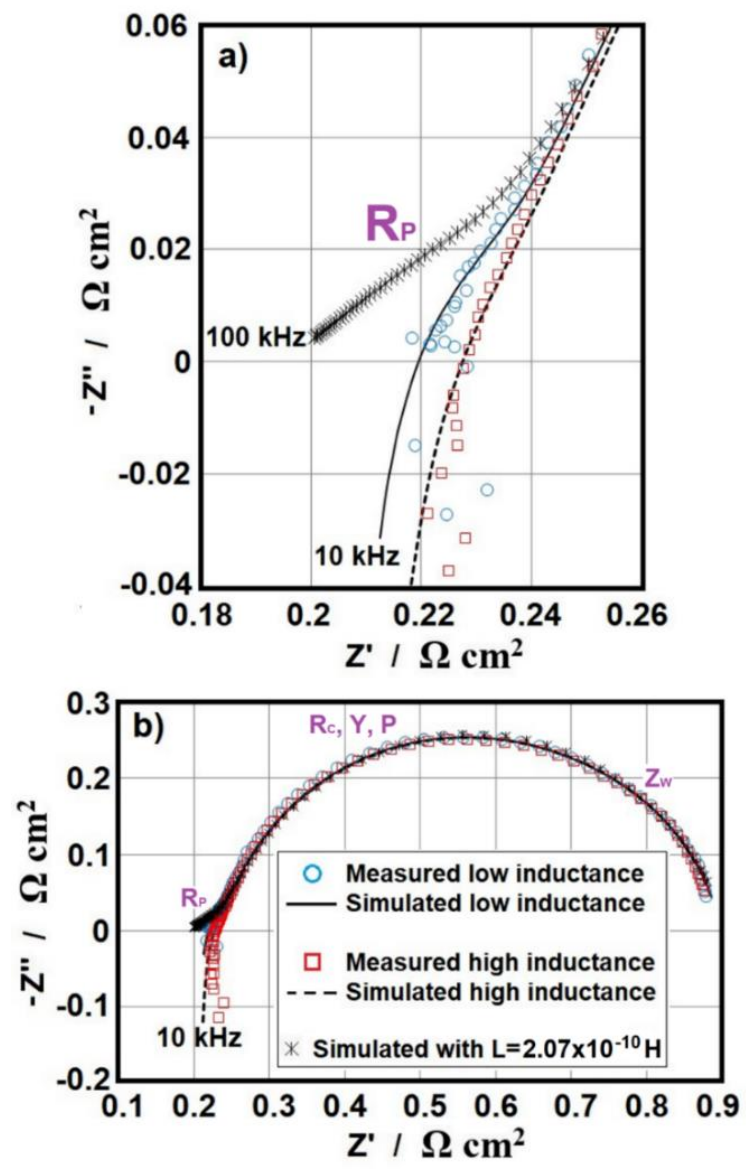

Figure 6 Simulated inductive effect at high frequencies on cathodic EIS measurements [38] using Eq. 9 with parameters shown in Table 2, a) high frequency region, b) full impedance spectrum.

The ohmic resistance of the PEFC has been calculated from EIS measurements where the imaginary component is equal to zero $Z^{\prime \prime}=0$ at high frequencies [36]. However, as demonstrated in Figures 5 and 6 , this could lead to incorrect results when comparing the Ohmic resistance in PEFCs from EIS measurements featuring a different inductive effect at high frequencies. The inductive effect at high frequencies attributed to the inductance of the cables connected between the PEFC and the load and during EIS tests deforms the high frequency region of the PEFC impedance spectrum and masks the ionic resistance in the catalyst layer as well [38]. 


\subsection{Inductive Loop at low Frequency}

The EEC shown in Figure 4 can also simulate the effect of inductive loops on the impedance spectrum at low frequencies. The parameter $Z_{a d}$ in Eq. 9 comprised the parameters $Y_{a d}$ and $R_{a d}$. These parameters are related to a faradaic process with adsorption as the ORR that takes places between the electrode/electrolyte interface can be governed by both the rate constants and the intermediate species adsorbed on the electrode. The simulation of the impedance spectrum shown in Figure 5 resulted in negative values for the parameters $Y_{a d}$ and $R_{a d}$, as shown in Table 1 . The negative value in the parameters is related to adsorbed species coverage $\varphi$ depending on potential $E(\mathrm{~d} \varphi / \mathrm{dE})$ in electrochemical systems with adsorbed intermediate species [43]. More recently, Klotz [44] reported that EIS measurements with positive imaginary components $Z$ " at low frequencies or inductive loops can also be predicted by applying an EEC comprising a negative capacitance to reproduce inductive loops in the positive half-plane of the Nyquist plot.

In this study, the impedance spectrum with low inductive loop at low frequencies shown in Figure 5 was simulated by reducing the parameter $Y_{a d}$ from -42.2 to $-172.2 \mathrm{~s}^{\mathrm{P}} \Omega^{-1} \cdot \mathrm{cm}^{-2}$ and by increasing the parameter $R_{\text {ad }}$ from -0.205 to $-0.026 \Omega . \mathrm{cm}^{2}$. The impedance spectrum with no inductive loop at low frequencies and shown in Figure 5 was simulated by considering the parameter $Z_{a d}=0$ in Eq. 9 . Similar to the inductive effect at high frequencies, the inductive loop also deforms the end-point at $Z^{\prime \prime}=0$ of the impedance spectrum at low frequencies, as shown in Figure 5. The inductive loop at low frequencies during EIS on PEFCS has been related to physical processes e.g. side reactions with intermediate species, carbon monoxide poisoning, and water transport characteristics during PEFC operation $[17,45,46]$. It may not be possible to reduce inductive loops at low frequencies in EIS measurements through a hardware modification as these representations on the impedance complex-plot can result from intrinsic phenomena during PEFC operation.

Different impedance models [24, 47-49] have been applied to EIS measurements of PEFCS to associate the inductive loops at low frequencies with electrochemical mechanisms during PEFC operation. In a previous study [22], inductive loops in EIS measurements carried out in a 4-cell opencathode PEFC stack were validated using an impedance model based on electrode theory and considering hydrogen peroxide $\mathrm{H}_{2} \mathrm{O}_{2}$ and platinum oxide PtO formation during the ORR. The operating conditions of the open-cathode PEFC stack and experimental setup for the EIS measurements can be found in a previous study [21]. In the same study [21], the EEC shown in Figure 4 was fitted with the EIS measurements carried out in the individual cells of the 4-cell opencathode PEFC stack.

In this study, a similar fitting procedure as considered in the previous study [21] is carried out in the EIS measurements of the whole 4-cell open-cathode PEFC stack at $0.3125 \mathrm{~A} / \mathrm{cm}^{2}$ using Eq. 9, as shown in Figure 7. For instance, Eq. 9 was initially fitted to the measured EIS spectrum shown in Figure 7 while neglecting the parameter $Z_{a d}$; thereafter the parameter $Z_{a d}$ was considered in Eq. 9 to predict the inductive loop at low frequencies. In addition, parameters from theoretical relations reported in the literature and through a graphical interpretation of the complex plot were considered [50]. Noting that the inductor element was neglected ( $L=0$ in Eq. 9) as no EIS measurements with positive imaginary components at high frequency were present. The simulated impedance response predicted by the EEC shown in Figure 4 and the simulated response from the impedance model considering $\mathrm{H}_{2} \mathrm{O}_{2}$ and $\mathrm{PtO}$ formation and reported in the previous study [22] have been compared to EIS measurements carried out in the whole 4-cell open-cathode PEFC stack at 
$0.3125 \mathrm{~A} / \mathrm{cm}^{2}$, as shown in Figure 7. Figure 7 demonstrates that both models can reproduce the EIS measurements of the 4-cell open-cathode PEFC stack in the frequency range from $10 \mathrm{kHz}$ to $0.1 \mathrm{~Hz}$. In addition, the simulated impedance response of both models was extended down to the frequency of $1 \times 10^{-9} \mathrm{~Hz}$ to emulate their impedance response with positive imaginary components $Z^{\prime \prime}$ until converging it with the value of the $\mathrm{DC}$ polarisation resistance.

The DC polarisation resistance can be calculated from the slope of the polarisation curve [51]. The DC polarisation resistance for the EIS measurements of the 4-cell open-cathode PEFC stack at $0.3125 \mathrm{~A} / \mathrm{cm}^{2}$ and shown in Figure 7 result in $2.53 \Omega . \mathrm{cm}^{2}$. More details about the calculation of the DC polarisation resistance at $0.3125 \mathrm{~A} / \mathrm{cm}^{2}$ from the polarisation curve measured off the 4-cell opencathode PEFC stack can be found in a previous study [22]. From Figure 7 it can be observed that different impedance models can reproduce the experimental EIS measurements presenting the inductive loop and also predict the impedance response with positive imaginary components $Z^{\prime \prime}$ until converging them with the DC polarisation resistance.

Additionally, Klotz [44] proposed that the time constant for an inductive loop would be where the imaginary components $Z^{\prime \prime}$ show a maximum value. The aforementioned proposition could lead to incorrect results if the time constant is calculated from a simulated impedance response rather than from real-world EIS measurements. Figure 7 shows a difference between the simulated inductive loops where the imaginary components $Z$ " show a maximum value. The maximum value of the simulated imaginary components using the circuit shown in Figure 4 was achieved at the frequency of $0.005 \mathrm{~Hz}$. The simulated impedance spectrum using the model from a previous study [22] predicted a maximum imaginary component $Z^{\prime \prime}$ at the frequency of $0.02 \mathrm{~Hz}$. In practice, it would be required to carry out EIS measurements at a very low frequency range (e.g. $1 \mu \mathrm{Hz}$ ) to validate inductive loops and hence calculate the time constant related to inductive loops, but it is not practical to wait such a long time for completion of the experimental tests.

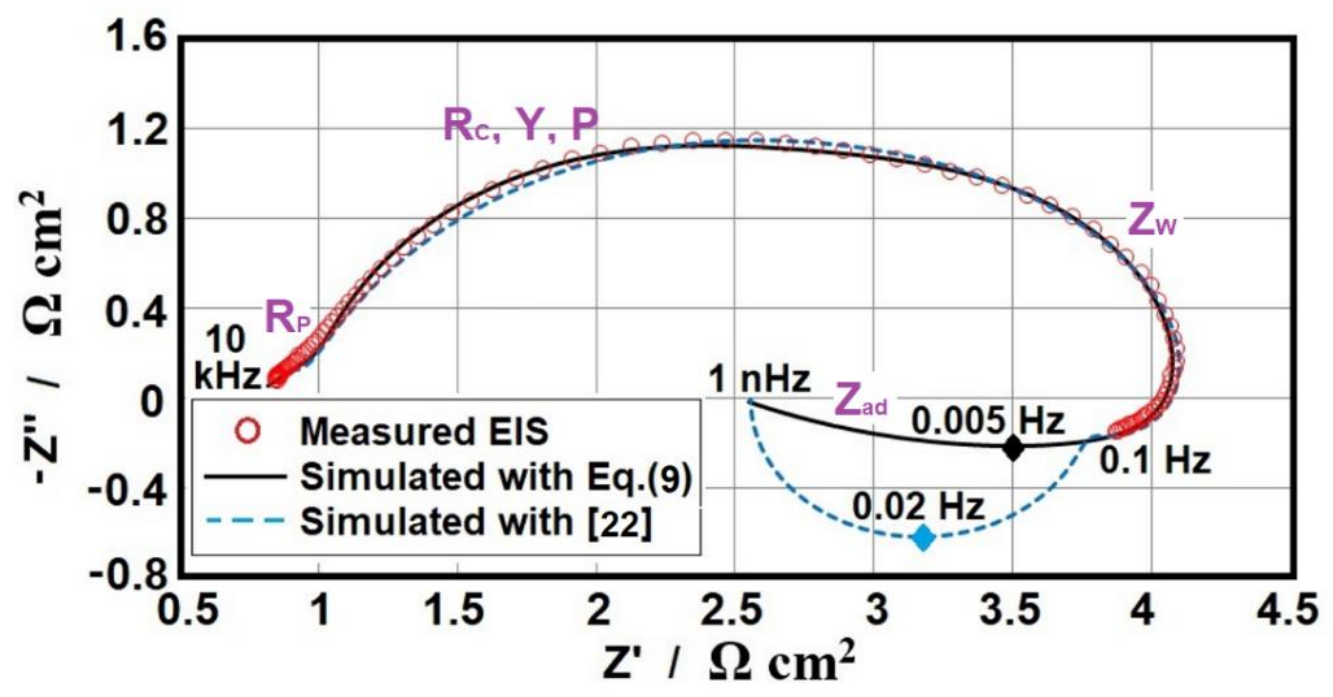

Figure 7 Comparison between EIS measurements [21] and simulated inductive loop predicted by Eq. 9 and the model from previous study [22]. The parameters from Eq. 9 are $R_{P}=0.73 \Omega . \mathrm{cm}^{2}, R_{C}=2.88 \Omega . \mathrm{cm}^{2}, Y=0.004 \mathrm{~s}^{P} \Omega^{-1} . \mathrm{cm}^{-2}, P=0.843, R_{W}=0.44 \Omega . \mathrm{cm}^{2}$, $T_{W}=0.024$ s., $R_{o h m}=0.75 \Omega . \mathrm{cm}^{2}, R_{a d}=-1.74 \Omega . \mathrm{cm}^{2}, Y_{a d}=-2.24 \mathrm{~s}^{\mathrm{P}} \Omega^{-1} . \mathrm{cm}^{-2}$. The parameters from the model simulating the dashed lines can be found elsewhere [22]. 
Figure 7 demonstrates the ambiguity that exists within the physical interpretation of inductive loops in EIS measurements of PEFCs. The validation and interpretation of inductive loops in EIS measurements in PEFCs needs further investigation as the interpretation of inductive loops within electrochemical processes in the PEFCs is still open to different interpretation. A generic impedance model of a PEFC which is capable of predicting the different mechanisms yielding the formation of inductive loops in EIS of PEFCs, such as side reactions with intermediate species during the ORR, carbon monoxide poisoning, and water transport characteristics, etc., is needed. The impedance model presented in this study and represented through Eq. 9 attributes the formation of inductive loops to side reactions with intermediate species during the ORR.

\section{Simulating EIS Measurements Featuring a Single Semicircle During High Current PEFC Operation.}

The presence of two semicircles in the Nyquist plot when carrying out EIS measurements in $\mathrm{H}_{2}$ /air PEFCs and increasing current demand is apparent $[12,27]$. As previously mentioned in section 3 and shown in Figure 5, the high frequency semicircle with negative imaginary components $Z^{\prime \prime}$ is mainly attributed to the driving force for the interfacial ORR and the low frequency semicircle with negative imaginary components $Z^{\prime \prime}$ is attributed to oxygen diffusion processes.

However, Figure 8 shows experimental cathodic EIS measurements carried out in a single PEFC and featuring a single semicircle with increasing current density. These EIS measurements were carried out in a $25 \mathrm{~cm}^{2} \mathrm{H}_{2}$ /air PEFC operated at 0.2 and $0.32 \mathrm{~A} / \mathrm{cm}^{2}$ and using a three-electrode configuration in the measurement system to separate cathodic EIS measurements from the total PEFC-EIS measurements. The operating conditions of the $25 \mathrm{~cm}^{2} \mathrm{H}_{2}$ /air PEFC and experimental setup for the EIS measurements shown in Figure 8 can be found in a previous study [23]. When EIS measurements feature a single semicircle in the Nyquist plot during high current PEFC operation, it is difficult to visualize in the Nyquist plot the processes related to the kinetics of the ORR and oxygen diffusion. Another example was reported by Yuan el at. [9]. The authors reported EIS measurements carried out in a $\mathrm{H}_{2}$ /air PEFC stack featuring a single semicircle with increasing current. The authors tried to estimate the processes related to the kinetics of the charge transfer during the ORR and oxygen diffusion in the Nyquist plot of the EIS measurements using the Randles EEC. However, the results showed that it was not possible to correctly estimate the kinetic and diffusion mechanisms using the Randles EEC as the estimated charge transfer resistance increased with increasing current density.

The EEC shown in Figure 4 was fitted to the EIS measurements shown in Figure 8 by considering parameters reported in the literature in the impedance model and reducing the number of parameters during the fitting process between EIS measurements and the simulated response. The parameter $Z_{a d}$ in the EEC was negligible as no inductive loops were manifested at low frequencies. The fitting process between the simulated response and EIS measurements was carried out in Matlab environment using a least square fitting method.

It has been considered that the Warburg component $Z_{W}$ represented in Eq. 2 can be applied to characterise the frequency response of oxygen diffusion in the GDLs [12, 27]. A recent study reported by Kulikovsky [52] derived an impedance equation to characterise the oxygen transport limitation in GDLs from PEFCs using EIS. The author also reported that the classic finite-length Warburg impedance $Z_{w}$ which is represented in Eq. 2 is not appropriate for oxygen transport analysis in GDLs of PEFCs. The author concluded that the diffusion impedance of the GDL resembles 
the impedance response of the finite-length Warburg when the double-layer capacitance of the catalyst layer is small.

In this study, the Warburg component $Z_{W}$ in Eq. 2 represents the frequency response of oxygen diffusion across the CCL during EIS. The EIS measurements shown in Figure 8 were accurately simulated by considering a value in the oxygen diffusion time constant $\tau_{W}$ within the order of $10^{-3} \mathrm{~s}$ [3] in the impedance model represented in Eq. 9. The time constant $\tau_{W}$ to diffuse oxygen through the $C C L$ is defined in Eq. 4 [21]. The oxygen diffusion time constant $\tau_{W}$ was increased by two orders of magnitude $10^{-1} \mathrm{~s}$ in the impedance model to separate the semicircles representing the charge transfer resistance during the ORR and the oxygen diffusion resistance at the frequency of $3.3 \mathrm{~Hz}$ as shown in Figure 8. Similar results have been reported in a previous study [23]. An increase in the oxygen time constant $\tau_{W}$ is equivalent to a decrease in the diffusion coefficient $D$ as expressed in Eq. 4. A decrease in the diffusion coefficient can be related to obstruction for oxygen diffusion through the porous media of the $\mathrm{CCL}$ in which the main path of oxygen diffusion would be the nafion/electrolyte solution surrounding the Pt/C agglomerates [23]. The simulated semicircle attributed to the charge transfer resistance during the ORR and represented in the frequency range from $10 \mathrm{kHz}$ to $3.3 \mathrm{~Hz}$ decreases with increasing current density from 0.2 to $0.32 \mathrm{~A} / \mathrm{cm}^{2}$. The simulated semicircle represented in the frequency range from $3.3 \mathrm{~Hz}$ to $0.3 \mathrm{~Hz}$ and attributed to oxygen transport limitations increases with increasing current density.

Also, as already mentioned, Klotz [44] reported that the time constant for a semicircle in the negative imaginary half-plane of the Nyquist plot has been related to the frequency at which the imaginary part shows a minimum value. Considering that the double layer capacitance between dissimilar materials e.g. carbon/nafion in the electrode has been calculated from a CPE using the following relation [53],

$$
C=Y\left(2 \pi f_{C}\right)^{P-1}
$$

where $f_{C}$ is the frequency at which the imaginary components $Z^{\prime \prime}$ of the EIS measurements shows a minimum value, and the parameters $Y$ and $P$ are related to a CPE. The frequency at the minimum value of the imaginary component $Z^{\prime \prime}$ for the measured spectrum shown in Figure 8 at $0.2 \mathrm{~A} / \mathrm{cm}^{2}$ was estimated to be $7.8 \mathrm{~Hz}$. For the simulated spectrum presenting two semicircles the capacitance between dissimilar materials in the electrode should be calculated from the frequency at which the first semicircle at high frequencies reaches its minimum value in the imaginary axis $Z^{\prime \prime}$. The minimum value of the imaginary component $Z^{\prime \prime}$ of the simulated high frequency semicircle shown in Figure 8 at $0.2 \mathrm{~A} / \mathrm{cm}^{2}$ was at the frequency of $6.15 \mathrm{~Hz}$. Thus, the calculated capacitance using Eq. 10 for the measured spectrum at $0.2 \mathrm{~A} / \mathrm{cm}^{2}$ and at the frequency of $7.8 \mathrm{~Hz}$ resulted in $18.8 \mathrm{mF} / \mathrm{cm}^{2}$ and for the simulated spectrum (dashed line) at $0.2 \mathrm{~A} / \mathrm{cm}^{2}$ resulted in $19.6 \mathrm{mF} / \mathrm{cm}^{2}$. It is known that the time to steady-state on spatial and temporal current distributions in the $\mathrm{CCL}$ is retarded with increasing the double layer capacitance in the electrode [54]. Therefore, the practice of calculating the capacitance effect in the electrode through EIS measurements comprising a single semicircle in the Nyquist plot could yield incorrect results if EIS measurements feature an overlapping effect between charge transfer and oxygen diffusion processes. The interpretation of electrochemical processes represented in EIS measurements can be obscure. Figure 8 demonstrates that an impedance model can decouple electrochemical processes and can provide an insight into the different phenomena during PEFC operation and represented at different frequencies in EIS measurements. 


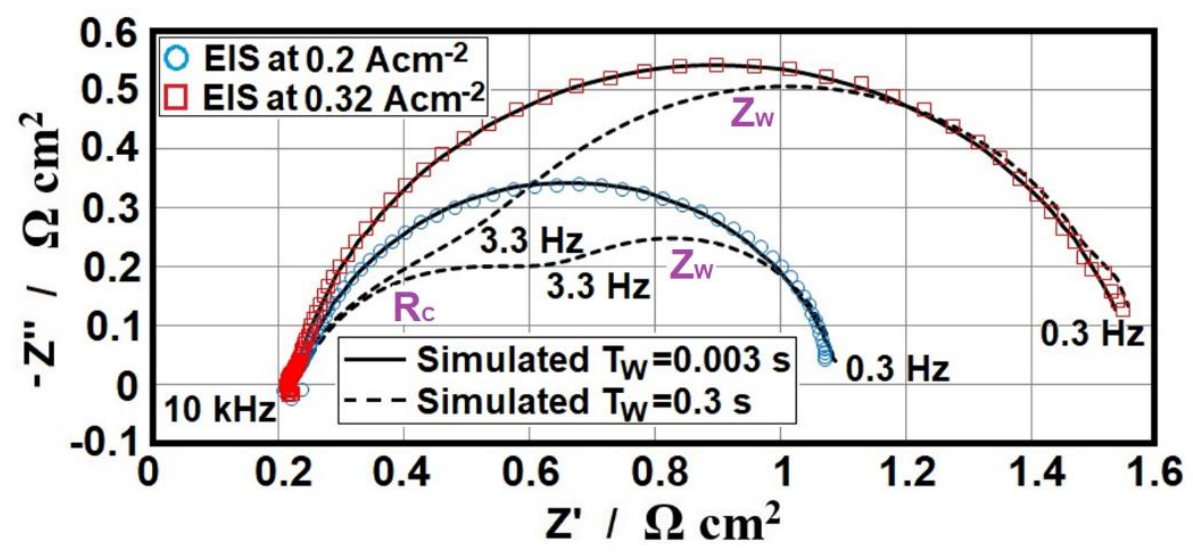

Figure 8 Comparison between measured [23] and simulated impedance spectrum from Eq. 9. Parameters for simulated spectrum at $0.2 \mathrm{~A} / \mathrm{cm}^{2}$ are: $R_{P}=0.1125 \Omega . \mathrm{cm}^{2}, R_{C}=0.41$ $\Omega . \mathrm{cm}^{2}, R_{W}=0.445 \Omega . \mathrm{cm}^{2}, T_{W}=0.003 \mathrm{~s}$ and $0.3 \mathrm{~s}$. Parameters for simulated spectrum at $0.32 \mathrm{~A} / \mathrm{cm}^{2} R_{P}=0.09 \Omega . \mathrm{cm}^{2}, R_{C}=0.3125 \Omega . \mathrm{cm}^{2}, R_{W}=1.02 \Omega . \mathrm{cm}^{2}, T_{W}=0.003 \mathrm{~s}$ and $0.3 \mathrm{~s}$.

\section{Conclusion}

This study has demonstrated that the assessment of EIS measurements of PEFCs represented in the Nyquist plot could be misled by the presence of inductive effects or EIS measurements with positive imaginary components at high and low frequencies. Inductive effects at high frequencies attributed to the intrinsic inductance of the electrical cables during EIS measurements can be reduced by hardware manipulation e.g. twisting electrical cables or using low inductive cables [38] connected between the PEFC and the load. Inductive loops at low frequencies could not be reduced by hardware manipulation as they can be a result of the frequency response of phenomenological processes of the PEFC during EIS measurements.

Furthermore, the EIS measurements with positive imaginary components $Z$ "' could lead to an incorrect interpretation of the electrochemical processes (e.g. ionic conduction through the PEM and catalyst layers, time constant calculation, etc.) represented in the Nyquist plot. Another effect that could also misinterpret electrochemical mechanisms represented in the Nyquist plot is the presence of a single semicircle during EIS measurements carried out in a PEFC during high current operation. Under this condition, it is difficult to assess through a qualitative analysis or graphical interpretation the contribution of charge transfer mechanisms during the ORR and oxygen diffusion mechanisms in the Nyquist plot. The application of semi-empirical impedance models with measured EIS impedance spectra can allow the estimation of the contribution of the charge transfer resistance during the ORR and oxygen transport limitations in EIS measurements featuring a single semicircle in the Nyquist plot. An erroneous calculation of the double layer capacitance effect in the electrode could also result from the presence of an overlapping effect between charge transfer mechanisms during the ORR and oxygen diffusion mechanisms in the Nyquist plot. The presence of inductive loops at low frequencies and overlapped mechanisms in impedance spectra of PEFCs could also lead to an erroneous estimation of time constants for prediction of spatial and temporal current distribution across the CCL.

To conclude, in this study, simulating the effect of EIS measurements with positive imaginary components $Z^{\prime \prime}$ at high and low frequencies on the Nyquist plot has been further demonstrated. 
Inductive effects from the measurement EIS system at high frequencies and inductive loops at low frequencies, attributed to phenomenological processes (e.g. side reactions with intermediate species) during PEFC operation, could yield uncertainties when monitoring the state of health, and consequent performance of different PEFCs (e.g flooding in the CCL, GDL and drying in the PEM) through a defined single frequency or a single measured value (e.g. EIS measurements at $Z^{\prime \prime}=0$ ) from EIS. The presence of single semicircles in EIS measurements carried out in PEFCs during high current operation could also yield uncertainties about the contribution of charge transfer mechanisms during the ORR and oxygen diffusion on the Nyquist complex impedance plot. The uncertainties in the impedance spectrum of the PEFC due to inductive effects and oxygen diffusion time constant may complicate the development of a generic algorithm to monitor performance of different PEFCS based on a single frequency or a single measured value from EIS. These considerations have guided the evaluation of the new simulations performed and based on the EEC represented through Eq. 9. The use of the validated impedance model represented through Eq. 9 within EIS measurements allows the correct interpretation and estimation of the physical processes in PEFCs despite artefacts from the measurement hardware as well as overlapping processes in the electrode during PEFC operation present in EIS measurements. The validated impedance model is capable of adapting to variations in PEFC impedance characteristics.

\section{Nomenclature}

$\begin{array}{lll}\mathrm{C}_{\mathrm{O}}^{*} & \text { oxygen concentration in the GDL-CCL interface } & \mathrm{mol} / \mathrm{cm}^{3} \\ \mathrm{D} & \text { diffusion coefficient } & \mathrm{m}^{2} / \mathrm{s} \\ \mathrm{j} & \text { imaginary component of a complex number } & \text { dimensionless } \\ \mathrm{L} & \text { inductance } & \mathrm{H} \\ \mathrm{P} & \text { parameter of constant phase element } & \text { dimensionless } \\ \mathrm{R} & \text { gas constant } & \mathrm{J} / \mathrm{mol} . \mathrm{K} \\ \mathrm{R}_{\mathrm{ad}} & \text { adsorbed intermediate species resistance } & \Omega . \mathrm{cm}^{2} \\ \mathrm{R}_{\mathrm{C}} & \text { charge transfer resistance } & \Omega . \mathrm{cm}^{2} \\ \mathrm{R}_{\mathrm{P}} & \text { ionic resistance } & \Omega . \mathrm{cm}^{2} \\ \mathrm{R}_{\mathrm{ohm}} & \text { total ohmic resistance } & \Omega . \mathrm{cm}^{2} \\ \mathrm{R}_{W} & \text { oxygen transport resistance } & \Omega . \mathrm{cm}^{2} \\ \mathrm{~T} & \text { temperature } & \mathrm{K} \\ \mathrm{Y} & \text { parameter of constant phase element } & \mathrm{s} / \Omega . \mathrm{cm}^{2} \\ Z & \text { Warburg impedance } & \Omega . \mathrm{cm}^{2} \\ \mathrm{z} & \text { number of electrons consumed } & \mathrm{dimensionless} \\ \omega & \text { angular frequency } & \mathrm{rad} / \mathrm{s} \\ \delta & \text { diffusion layer } & \mathrm{m} \\ \tau_{W} & \text { diffusion time constant } & \mathrm{s} \\ & & \end{array}$




\section{Author Contributions}

Samuel Cruz-Manzo did all the research work of this study.

\section{Competing Interests}

The author has declared that no competing interests exist.

\section{References}

1. Ciureanu $M$, Roberge R. Electrochemical impedance study of PEM fuel cells. Experimental diagnostics and modeling of air cathodes. J Phys Chem B. 2001; 105: 3531-3539.

2. Paganin VA, Oliveira CLF, Ticianelli EA, Springer TE, Gonzalez ER. Modelistic interpretation of the impedance response of a polymer electrolyte fuel cell. Electrochim Acta. 1998; 43: 37613766.

3. Springer TE, Zawodzinski TA, Wilson MS, Gottesfeld S. Characterization of polymer electrolyte fuel cells using AC impedance spectroscopy. J Electrochem Soc. 1996; 143: 587.

4. Schiefer A, Heinzmann M, Weber A. Inductive low-frequency processes in PEMFC-impedance spectra. Fuel Cells. 2020; 20:499-506.

5. Kosakian A, Urbina LP, Heaman A, Secanell M. Understanding single-phase water-management signatures in fuel-cell impedance spectra: A numerical study. Electrochim Acta. 2020; 350: 136204.

6. Mocoteguy P, Ludwig B, Beretta D, Pedersen T. Study of the impact of water management on the performance of PEMFC commercial stacks by impedance spectroscopy. Int J Hydrog Energy. 2020; 45: 16724-16737.

7. Kurz T, Hakenjos A, Krämer J, Zedda M, Argert C. An impedance-based predictive control strategy for the state-of-health of PEM fuel cell stacks. J Power Sources. 2008; 180: 742-747.

8. Mérida W, Harrington DA, Le Canut JM, McLean G. Characterisation of proton exchange membrane fuel cell (PEMFC) failures via electrochemical impedance spectroscopy. J Power Sources. 2006; 161: 264-274.

9. Yuan X, Sun JC, Blanco M, Wang H, Zhang J, Wilkinson DP. AC impedance diagnosis of a $500 \mathrm{~W}$ PEM fuel cell stack: Part I: Stack impedance. J Power Sources. 2006; 161: 920-928.

10. Romero-Castanon T, Arriaga LG, Cano-Castillo U. Impedance spectroscopy as a tool in the evaluation of MEA's. J Power Sources. 2003; 118: 179-182.

11. Freire TJP, Gonzalez ER. Effect of membrane characteristics and humidification conditions on the impedance response of polymer electrolyte fuel cells. J Electroanal Chem. 2001; 503: 57-68.

12. Fouquet N, Doulet C, Nouillant C, Dauphin-Tanguy G, Ould-Bouamama B. Model based PEM fuel cell state-of-health monitoring via ac impedance measurements. J Power Sources. 2006; 159: 905-913.

13. Makharia R, Mathias MF, Baker DR. Measurement of catalyst layer electrolyte resistance in PEFCs using electrochemical impedance spectroscopy. J Electrochem Soc. 2005; 152: A970.

14. Savova-Stoynov B, Stoynov ZB. Analysis of the inductance influence on the measured electrochemical impedance. J Appl Electrochem. 1987; 17: 1150-1158.

15. Göhr H, Mirnik M, Schiller CA. Distortions of high frequency electrode impedance: Their causes and how to avoid them. J Electroanal Chem Interfacial Electrochem. 1984; 180: 273-285. 
16. Roy SK, Orazem ME. Analysis of flooding as a stochastic process in polymer electrolyte membrane (PEM) fuel cells by impedance techniques. J Power Sources. 2008; 184: 212-219.

17. Wagner N, Schulze M. Change of electrochemical impedance spectra during CO poisoning of the Pt and Pt-Ru anodes in a membrane fuel cell (PEFC). Electrochim Acta. 2003; 48: 3899-3907.

18. Pivac I, Barbir F. Inductive phenomena at low frequencies in impedance spectra of proton exchange membrane fuel cells-A review. J Power Sources. 2016; 326: 112-119.

19. Weiß A, Schindler S, Galbiati S, Danzer MA, Zeis R. Distribution of relaxation times analysis of high-temperature PEM fuel cell impedance spectra. Electrochim Acta. 2017; 230: 391-398.

20. Schichlein H, Müller AC, Voigts $M$, Krügel A, Ivers-Tiffée E. Deconvolution of electrochemical impedance spectra for the identification of electrode reaction mechanisms in solid oxide fuel cells. J Appl Electrochem. 2002; 32: 875-882.

21. Cruz-Manzo S, Chen R. An electrical circuit for performance analysis of polymer electrolyte fuel cell stacks using electrochemical impedance spectroscopy. J Electrochem Soc. 2013; 160: F1109.

22. Cruz-Manzo S, Perezmitre-Cruz C, Greenwood P, Chen R. An impedance model for analysis of EIS of polymer electrolyte fuel cells under platinum oxidation and hydrogen peroxide formation in the cathode. J Electroanal Chem. 2016; 771: 94-105.

23. Cruz-Manzo S, Chen R. Rama P. Study of current distribution and oxygen diffusion in the fuel cell cathode catalyst layer through electrochemical impedance spectroscopy. Int J Hydrogen Energy. 2013; 38: 1702-1713.

24. Roy SK, Orazem ME, Tribollet B. Interpretation of low-frequency inductive loops in PEM fuel cells. J Electrochem Soc. 2007; 154: B1378.

25. Wagner N, Gülzow E. Change of electrochemical impedance spectra (EIS) with time during COpoisoning of the Pt-anode in a membrane fuel cell. J Power Sources. 2004; 127: 341-347.

26. Boillot M, Bonnet C, Didierjean S, Lapicque F. Investigation of the response of separate electrodes in a polymer electrolyte membrane fuel cell without reference electrode. J Appl Electrochem. 2007; 37: 103-110.

27. Malevich D, Halliop E, Peppley BA, Pharoah JG, Karan K. Investigation of charge-transfer and mass-transport resistances in PEMFCs with microporous layer using electrochemical impedance spectroscopy. J Electrochem Soc. 2008; 156: B216.

28. Ambrosi V, Di Sarli A. Development of a mathematical treatment for electrochemical impedance data obtained from coated metals: Part 1. Anti-Corros Method M. 1993; 40: 4-9.

29. Ciureanu $\mathrm{M}$, Wang $\mathrm{H}$. Electrochemical impedance study of electrode-membrane assemblies in PEM fuel cells: I electro-oxidation of $\mathrm{H}_{2}$ and $\mathrm{H} 2 / \mathrm{CO}$ mixtures on Pt-based gas-diffusion electrodes. J Electrochem Soc. 1999; 146: 4031.

30. Venkataraman R, Kunz HR, Fenton JM. Development of new CO tolerant ternary anode catalysts for proton exchange membrane fuel cells. J Electrochem Soc. 2003; 150: A278.

31. Ciureanu M, Wang H. Electrochemical impedance study of anode CO-poisoning in PEM fuel cells. J New Mat Electr Sys. 2000; 3: 107-119.

32. Eikerling $M$, Kornyshev AA. Electrochemical impedance of the cathode catalyst layer in polymer electrolyte fuel cells. J Electroanal Chem. 1999; 475: 107-123.

33. Lefebvre MC, Martin RB, Pickup PG. Characterization of ionic conductivity profiles within proton exchange membrane fuel cell gas diffusion electrodes by impedance spectroscopy. Electrochem Solid State Lett. 1999; 2: 259. 
34. Suzuki T, Murata H, Hatanaka T, Morimoto $\mathrm{Y}$. Analysis of the catalyst layer of polymer electrolyte fuel cells. R\&D Rev Toyota CRDL. 2003; 39: 33-38.

35. Hou J, Song W, Yu H, Fu Y, Hao L, Shao Z, et al. lonic resistance of the catalyst layer after the PEM fuel cell suffered freeze. J Power Sources. 2008; 176: 118-121.

36. Li G, Pickup PG. Ionic conductivity of PEMFC electrodes: Effect of Nafion loading. J Electrochem Soc. 2003; 150: C745.

37. Bard AJ, Faulkner LR. Fundamentals and applications. Electrochem Methods. 2001; 2: 580-632.

38. Cruz-Manzo S, Chen R, Rama P. Inductive effect on the fuel cell cathode impedance spectrum at high frequencies. J Fuel Cell Sci Tech. 2012; 9: 051002.

39. Cruz-Manzo S, Chen R. Electrochemical impedance study on estimating the mass transport resistance in the polymer electrolyte fuel cell cathode catalyst layer. J Electroanal Chem. 2013; 702: 45-48.

40. Cruz-Manzo S, Chen R. A generic electrical circuit for performance analysis of the fuel cell cathode catalyst layer through electrochemical impedance spectroscopy. J Electroanal Chem 2013; 694: 45-55.

41. Halvorsen IJ, Privac I, Bezmalinović D, Barbir F, Zenith F. Electrochemical low-frequency impedance spectroscopy algorithm for diagnostics of PEM fuel cell degradation. Int J Hydrogen Energy. 2020; 45: 1325-1334.

42. Niya SM, Phillips RK, Hoorfar M. Process modeling of the impedance characteristics of proton exchange membrane fuel cells. Electrochim Acta. 2016; 191: 594-605.

43. Bai L, Conway BE. Complex behavior of Al dissolution in non-aqueous medium as revealed by impedance spectroscopy. J Electrochem Soc. 1990; 137: 3737.

44. Klotz D. Negative capacitance or inductive loop? - A general assessment of a common low frequency impedance feature. Electrochem Commun. 2019; 98: 58-62.

45. Wiezell K, Gode P, Lindbergh G. Steady-state and EIS investigations of hydrogen electrodes and membranes in polymer electrolyte fuel cells: I. Modeling. J Electrochem Soc. 2006; 153: A749.

46. Schneider IA, Bayer MH, Wokaun A, Scherer GG. Impedance response of the proton exchange membrane in polymer electrolyte fuel cells. J Electrochem Soc. 2008; 155: B783.

47. Mathias M, Baker D, Zhang J, Liu Y, Gu W. Frontiers in application of impedance diagnostics to H2-fed polymer electrolyte fuel cells. ECS Trans. 2008; 13: 129.

48. Setzler BP, Fuller TF. A physics-based impedance model of proton exchange membrane fuel cells exhibiting low-frequency inductive loops. J Electrochem Soc. 2015; 162: F519.

49. Cruz-Manzo S, Chen R, Greenwood P. An impedance model for analysis of EIS of polymer electrolyte fuel cells under hydrogen peroxide formation in the cathode. J Electroanal Chem. 2015; 745: 28-36.

50. Cruz-Manzo S, Cano-Castillo U, Greenwood P. Impedance study on estimating electrochemical mechanisms in a polymer electrolyte fuel cell during gradual water accumulation. Fuel Cells. 2019; 19: 71-83.

51. Wagner N. Characterization of membrane electrode assemblies in polymer electrolyte fuel cells using ac impedance spectroscopy. J Appl Electrochem. 2002; 32: 859-863.

52. Kulikovsky $A$. Why impedance of the gas diffusion layer in a PEM fuel cell differs from the Warburg finite-length impedance? Electrochem Commun. 2017; 84: 28-31.

53. Hsu CH, Mansfeld F. Concerning the conversion of the constant phase element parameter Y0 into a capacitance. Corrosion. 2001; 57: 747-748. 
54. Cruz-Manzo S, Rama P, Chen R. The low current electrochemical mechanisms of the fuel cell cathode catalyst layer through an impedance study. J Electrochem Soc. 2010; 157: B400.

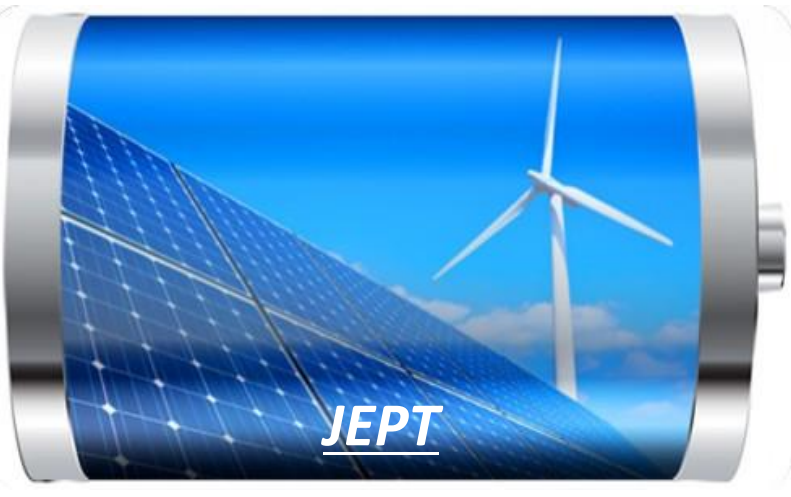

Enjoy JEPT by:

1. Submitting a manuscript

2. Joining in volunteer reviewer bank

3. Joining Editorial Board

4. Guest editing a special issue

For more details, please visit:

http://www.lidsen.com/journal/jept 